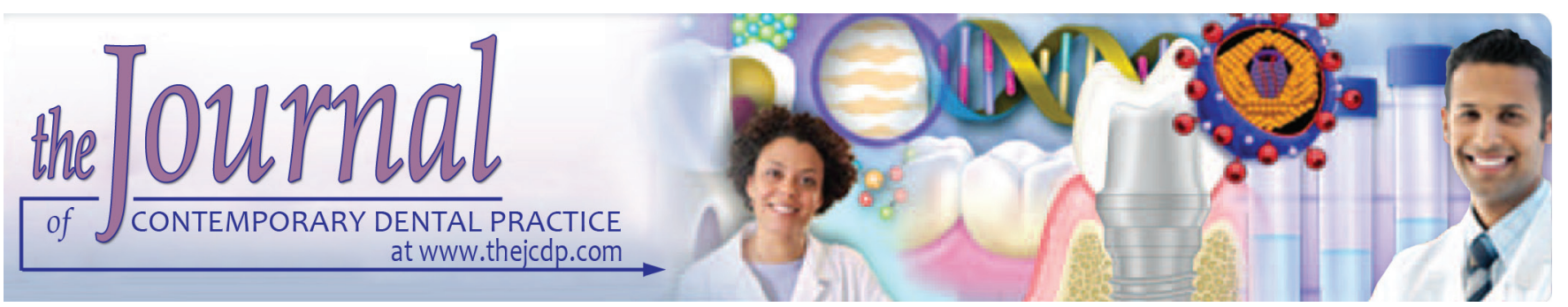

\title{
Chemical and Topographic Analysis of Eight commercially Available Dental Implants
}

\author{
${ }^{1}$ Mogammad T Peck, ${ }^{2}$ Bruno R Chrcanovic
}

\begin{abstract}
Background: Surface characterization of dental implants allows us to better understand the effects of the implant on the host biological response. In this study, we analyzed and compared these characteristics among implants commercially available in South Africa.
\end{abstract}

Materials and methods: Eight implants from different manufacturers were chosen for analysis (Touareg, ICE, (R)Evolutions, Uniti, AnyRidge, MIS, Ivory-QSI, Southern), using scanning electron microscopy (SEM), interferometry, and energy dispersive $\mathrm{X}$-ray spectroscopy to study the surface chemical composition and morphology.

Results: The results indicate that variations in manufacturer processes result in implant surfaces that are distinctly different from one another. Most implants presented a moderately rough surface with sandblasted-only implant surfaces having a lower mean value of $S_{a}$ when compared with sandblasted and acidetched surfaces. Carbon contamination was detected on all the implants and that of aluminum on five implant surfaces. Ca and $P$ were detected on the surface of Touareg implants, indicating the manufacturer's attempt to enhance osseointegration.

Conclusion: The surface of the implants showed a range of chemical, physical properties, and surface topographies.

Clinical significance: The results indicate that implant surface treatment is not standardized. This may have clinical implications. Further clinical research is required.

Keywords: Chemical analysis, Implant surface, Roughness, Titanium.

How to cite this article: Peck MT, Chrcanovic BR. Chemical and Topographic Analysis of Eight commercially Available Dental Implants. J Contemp Dent Pract 2016;17(5):354-360.

\footnotetext{
${ }^{1}$ Department of Oral Medicine and Periodontology, University of the Western Cape, Cape Town, South Africa

${ }^{2}$ Department of Prosthodontics, Faculty of Odontology, Malmö University, Malmö, Sweden

Corresponding Author: Mogammad T Peck, Department of Oral Medicine and Periodontology, University of the Western Cape, Cape Town, South Africa, e-mail: mpeck@uwc.ac.za
}

\section{Source of support: Nil}

Conflict of interest: None

\section{INTRODUCTION}

South African dental practices have been exposed to international dental implant manufacturers for the past 3 decades. This exposure was however limited, with clinicians only having a choice of less than five companies during that period. In recent years, this scenario has changed dramatically, with a myriad of international companies entering the market during the last 6 years. Many of these were newly introduced implants; although widely used among local dental practitioners, the manufacturers provided limited independent scientific information about the characteristics of their products. Clinicians therefore chose implants based on personal bias, cost, company support, and brand recognition. Research indicates that the surface structure of dental implants both in terms of chemical make-up and surface characteristics is a key component in terms of osseointegration and longevity of the product. ${ }^{1}$ These are therefore important factors in selecting implants when treating patients. Implant surface characterization provides a scientific basis for us to better understand the effects of the implant on the host biological response. ${ }^{2}$ In this study, we analyzed and compared these characteristics among implants commercially available in South Africa.

\section{MATERIALS AND METHODS}

Eight implants from different manufacturers were chosen for analysis, all available in the South African market. Detailed information about the implants is recorded in Table 1. For each implant type, four specimens were acquired from the manufacturers or local distributors. The implants were received in their original packaging, and 
Chemical and Topographic Analysis of Eight commercially Available Dental Implants

Table 1: Implants included in the study

\begin{tabular}{lll}
\hline Implant & Manufacturer & Surface treatment \\
\hline Touareg & Adin Dental Implants Systems Ltd., Afula, Israel & Sandblasting (calcium phosphate resorbable blast media) \\
ICE & Alpha-Bio Tec Ltd., Petach-Tikva, Israel & Sandblasting and acid-etching \\
(R)Evolutions & Champions-Implants GmbH, Flonheim, Germany & Acid-etched and zircon-blasted \\
Uniti & Equinox Medical Technologies B.V., Zeist, Netherlands & Sandblasting \\
AnyRidge & MegaGen Implants Co., Gyeongsan-si, South Korea & Sandblasting and acid-etching, calcium-coated \\
MIS & MIS Implant Technologies Ltd., Tel-Aviv, Israel & Sandblasting and acid-etching \\
Ivory-QSI & Ritter Implants GmbH \& Co., Biberach, Germany & Sandblasting and acid-etching (Ti6Al4V) \\
Southern Tapered & Southern Implants, Irene, South Africa & Sandblasting and acid-etching \\
\hline
\end{tabular}

these were only opened at the start of the investigation. Care was taken to meticulously handle all the samples so as to prevent contamination.

Similar to previous studies, the surface morphology of the samples was examined using scanning electron microscopy (Auriga field emission high-resolution scanning electron microscopy (SEM), Carl Zeiss Microscopy $\mathrm{GmbH}$, Jena, Germany). The secondary electron detection mode with an acceleration voltage of $5 \mathrm{kV}$ was selected for SEM analysis and the vacuum pressure was maintained at about $2.2 \times 10^{-10}$ torr. The filament current was $2.359 \mathrm{~A}$. The same magnifications were selected for all samples $(24 \times$, $1000 \times, 5000 \times$, and $10000 \times)$, from a spot of the threaded region of the implants, which was selected randomly.

Implant threads were examined with interferometry using a MicroXAM instrument (ADE Phase Shift Technology, Inc., Tuczon, USA), in order to characterize the surface roughness at the micrometer level. Three implants of each group were investigated, and sampling for each implant was performed at nine different positions (three top areas, three valley areas, and three flank areas), giving a total of 27 measurements, with a scanning area of $200 \times 260 \mu \mathrm{m}$. Surfascan software version 4.2.4.1 (HommelEtamic GmbH, Villingen-Schwenningen, Germany) was used to calculate the three following topographical parameters, according to a suggested guideline ${ }^{3}$ : $S_{a}(\mu m)=$ average height deviation from a mean plane, $S_{\mathrm{dr}}(\%)=$ developed surface ratio, and $S_{\mathrm{ds}}\left(\mu \mathrm{m}^{-2}\right)=$ density of summits. Before the parametrical calculation could be evaluated, the waviness from the surface was removed using a $50 \times 50 \mu \mathrm{m}$ Gaussian filter. The images of the topographic scans were obtained using the software MontainsMap 6 (Digital Surf, Besançon, France), and the scans were subjected to leveling and Gaussian filtering with a cut-off of $50 \mu \mathrm{m}$. A statistical analysis of the mean values of the surface roughness parameters was composed and compared with one-way analysis of variance (ANOVA), since a normal distribution of the variables was observed by the Kolmogorov-Smirnov test. A Tukey's honest significant difference test was carried out to determine means that were significantly different from each other. The degree of statistical significance was considered $(\mathrm{p}<0.05)$. The statistical analysis was performed using the Statistical Package for the Social Sciences (SPSS) version 20 software (SPSS Inc., Chicago, USA).

Energy dispersive X-ray spectroscopy (EDS) - Auriga field emission high-resolution scanning electron microscopy, Carl Zeiss Microscopy GmbH, Jena, Germany) was used to analyze the surface chemical composition of the threaded area of the implants. Three measurements of each group were taken to determine the elemental chemical composition of the surface.

\section{RESULTS}

\section{Scanning Electron Microscopy Analysis}

Figures $1 \mathrm{~A}$ to $\mathrm{H}$ revealed differences between the surfaces of the implant groups as measured by SEM. These differences were most likely due to differences in the surface treatment processes carried out by the manufacturers. The sandblasted and acid-etched surfaces showed areas of pronounced strain caused by the impact of sandblasting particles and the subtle action of acidetching, with differences in the dimension of the cavities / pits. A similar surface pattern was observed between the implants ICE, (R)Evolutions, and MIS, with flat areas with small circular pits. These small pits were almost absent on the Ivory-QSI implants surface. Touareg and Uniti implants (only sandblasted) showed facets produced by the blasting process, without the smoothening caused by etching procedures. Even though subjected to sandblasting plus acid-etching, Southern implants showed a pattern of sandblasted-only surface. AnyRidge implants showed the presence of short rods throughout the surface, probably related to the $\mathrm{CaP}$ deposition performed after the sandblasting and acid-etching.

\section{Interferometry Analysis}

An analysis of the qualitative and quantitative surface topography showed different degrees of roughness for the various samples examined. The topographic maps obtained by interferometry showed, qualitatively, the difference in roughness between the eight surfaces (Figs 2A to $\mathrm{H}$ ). 

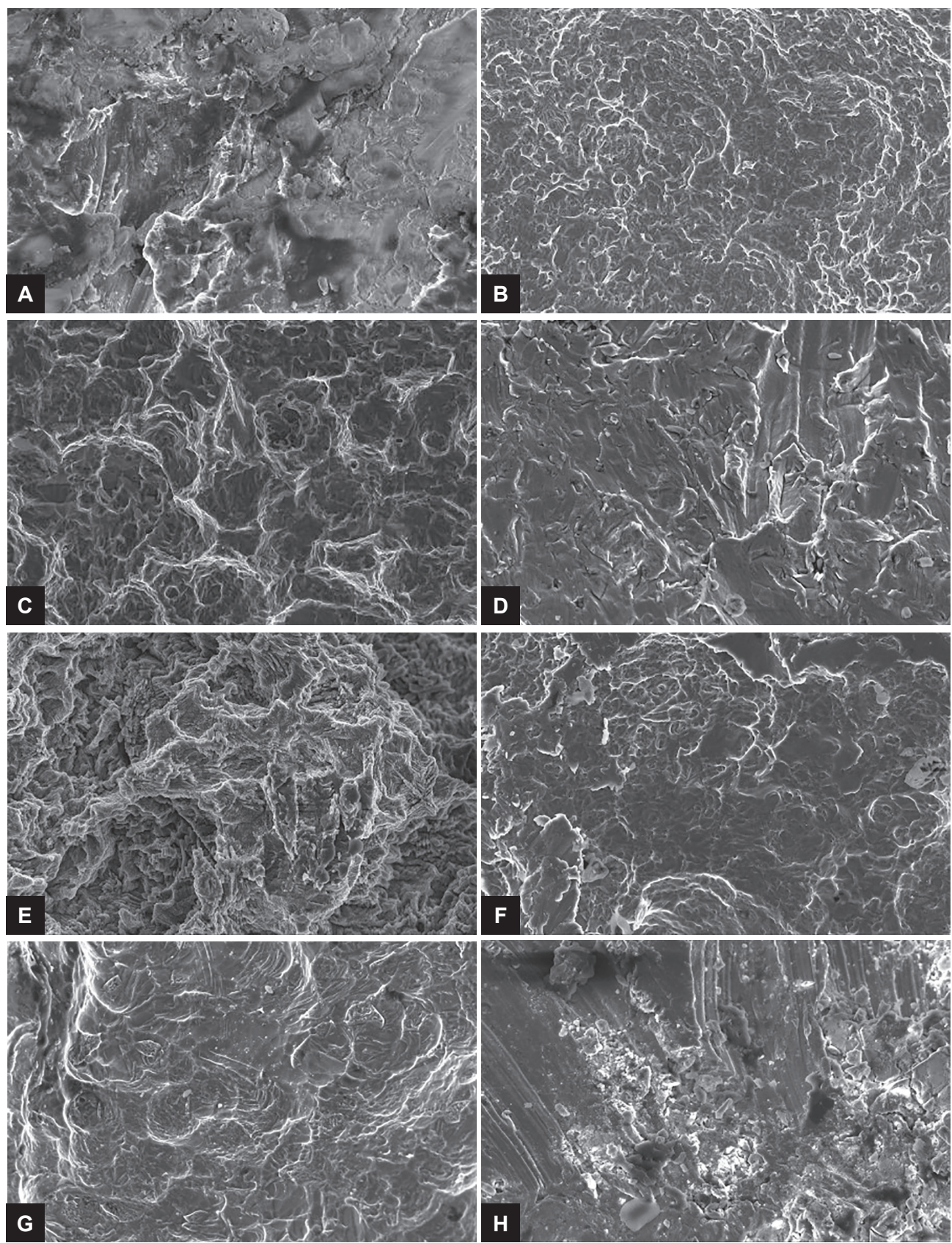

Figs 1A to H: Scanning electron microscopy pictures of (A) Touareg; (B) ICE; (C) (R)Evolutions; (D) Uniti; (E) AnyRidge; (F) MIS; (G) Ivory-QSI; and (H) Southern implants (original magnification $5000 \times$; scale bar $1 \mu \mathrm{m})$

Table 2 shows the mean values of three-dimensional (3D) roughness parameters for the implant groups. Only two groups (Touareg and Uniti) showed $S_{a}$ mean values lower than $1.0 \mu \mathrm{m}$.

\section{Energy Dispersive X-ray Spectroscopy Analysis}

The EDS analysis of the threaded surfaces of the implants showed that titanium was detected in all groups, and it was the element with the highest atomic concentration in six of the eight groups (Table 3). Carbon was also detected on the surface of all groups. After titanium and carbon, the most prevalent element was aluminum (5 groups), followed by oxygen (4 groups); calcium (3 groups); silicon (2 groups); and phosphor, iron, and fluorine (1 group each).

\section{DISCUSSION}

The present study to the best of the knowledge of the authors is the first of its kind carried out in South Africa. The results may prompt better selection of implants for treatment and may stimulate further clinical research to determine the clinical efficacy of these products. The results indicate that variation in manufacturer processes results in implant surfaces that are not homogenous and are distinctly different from one another. 


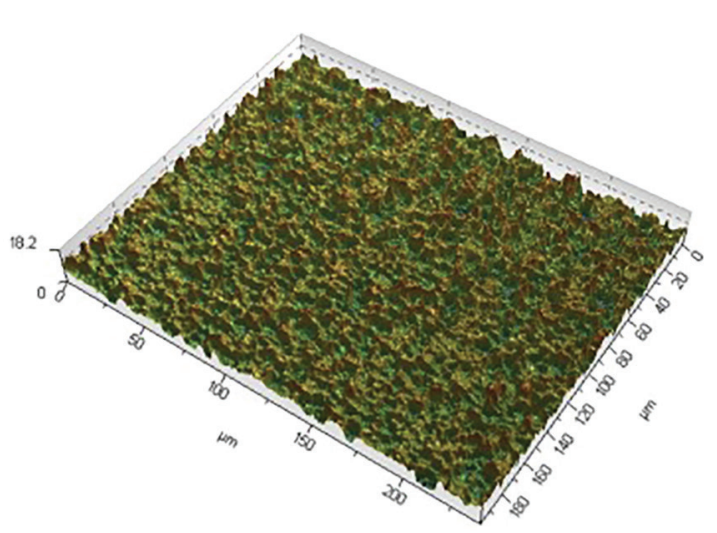

A

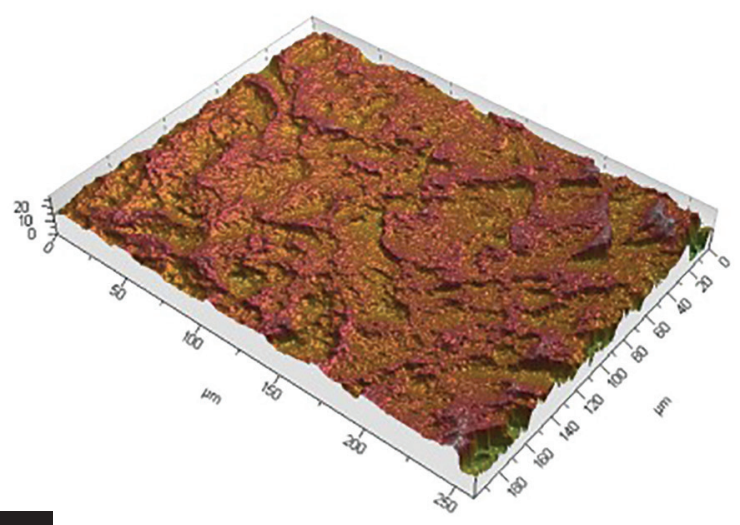

C

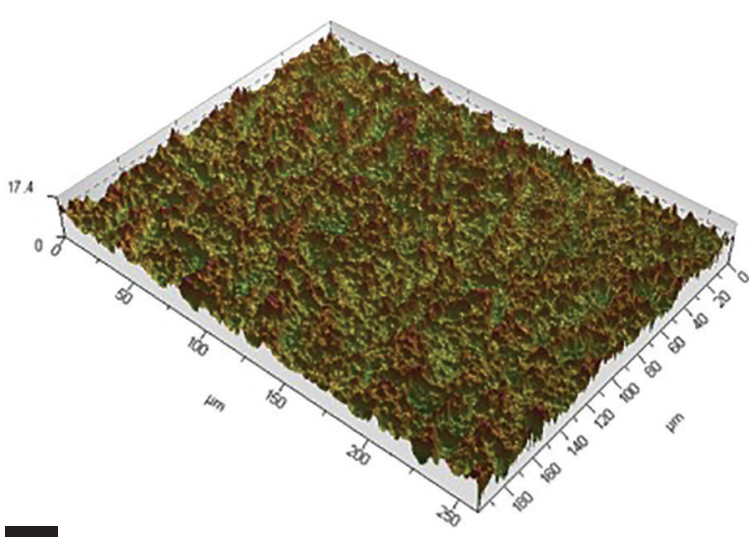

E

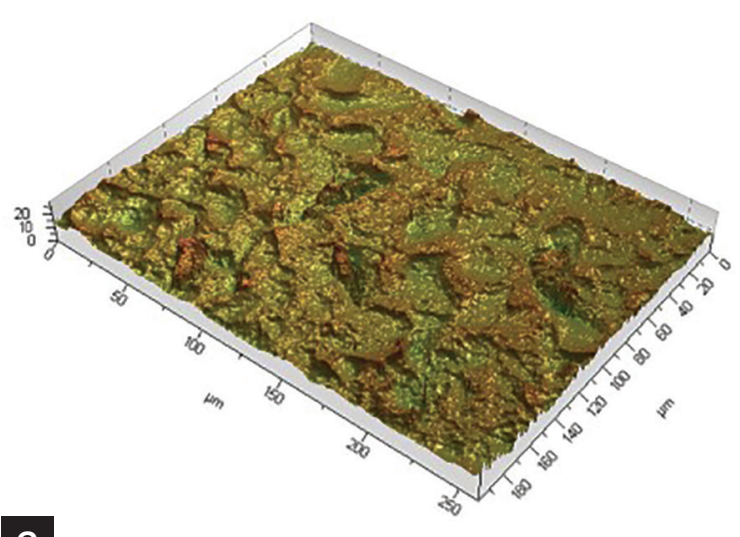

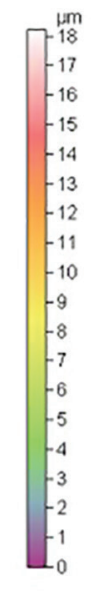

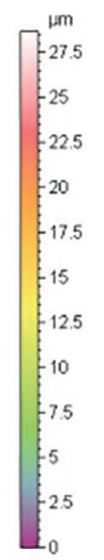

B
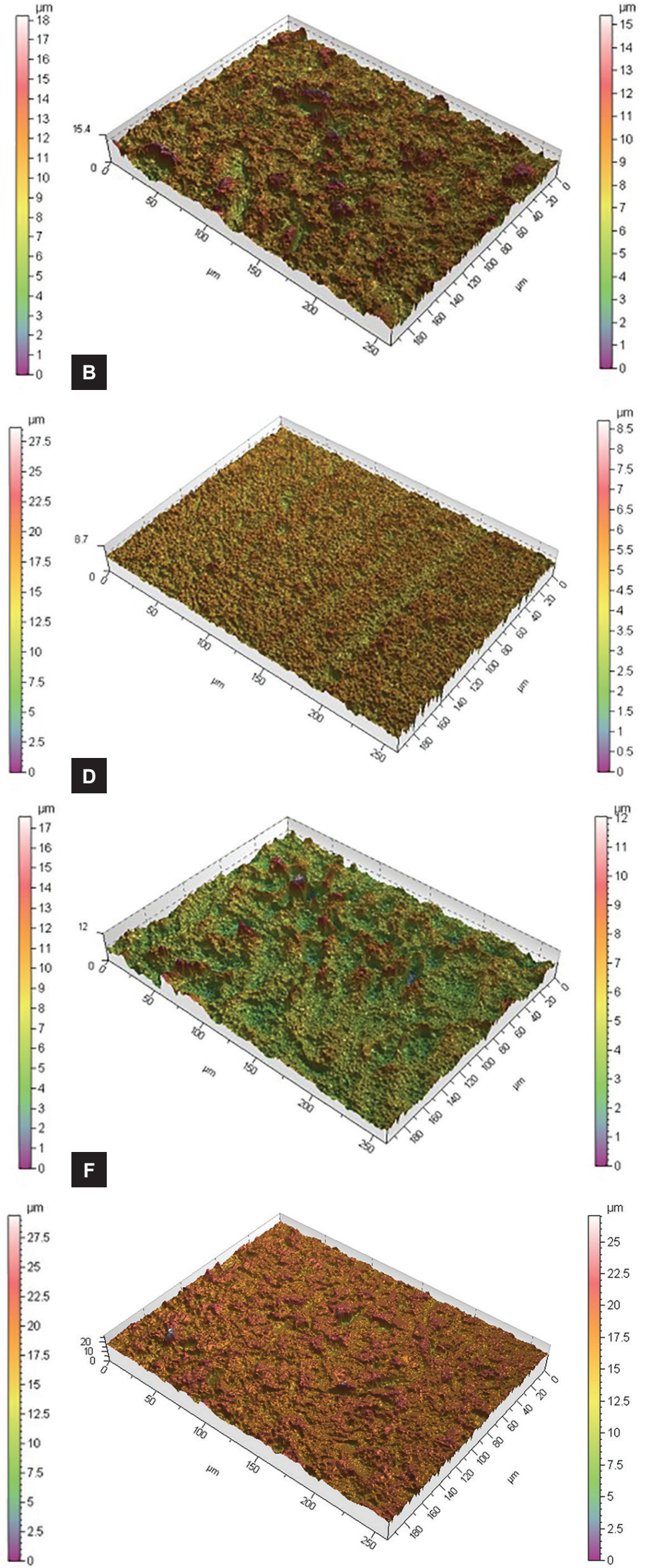

$\mathrm{mm}$
-15
-14
-13
-12
-11
-10
-9
-8
-7
-6
-5
-4
-3
-2
-1
0
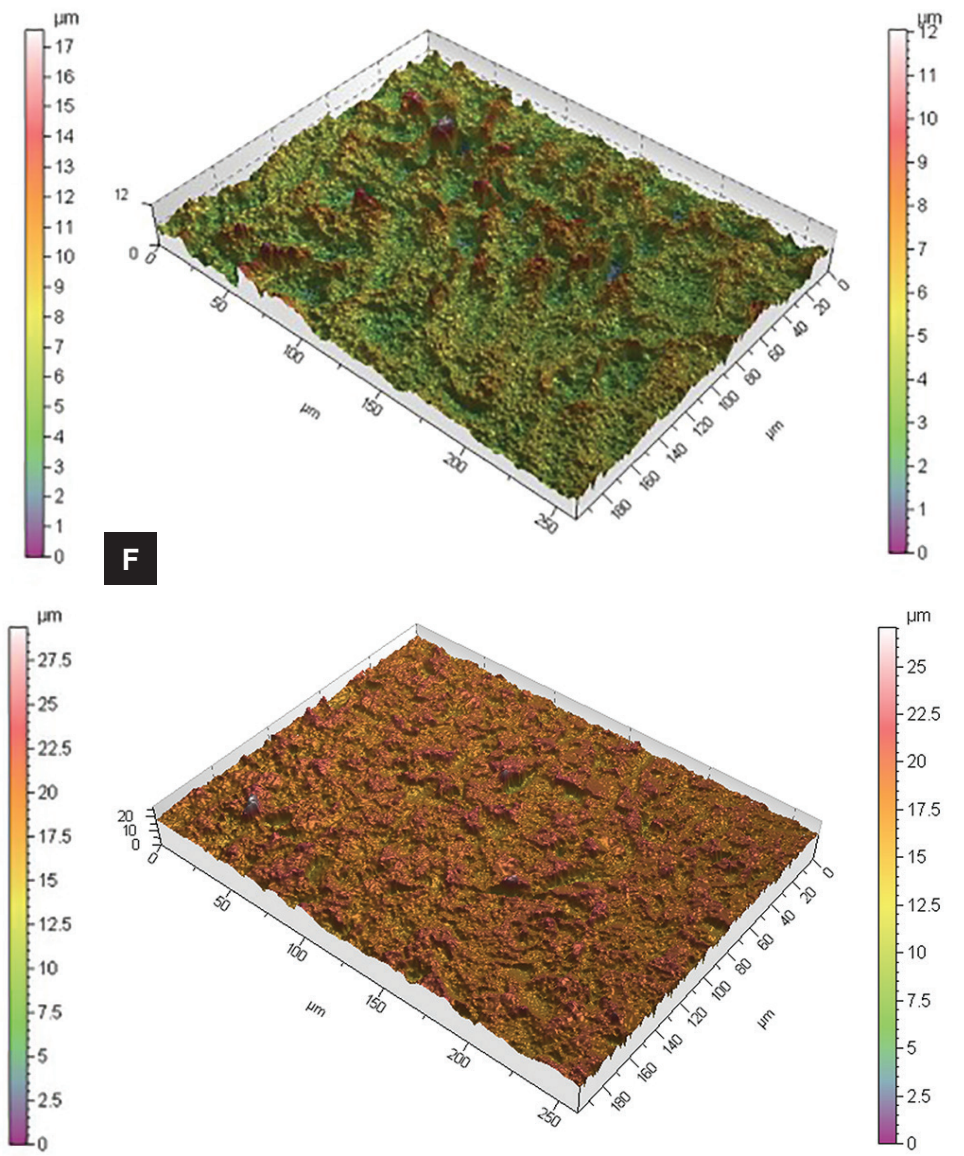

Figs 2A to H: Interferometry topography maps for: (A) Touareg; (B) ICE; (C) (R)Evolutions; (D) Uniti; (E) AnyRidge; (F) MIS; (G) Ivory-QSI; and (H) Southern implants (scanning area: $200 \times 260 \mu \mathrm{m}$ ) 
Table 2: Mean values ( \pm SD; 27 measurements) of the three-dimensional roughness parameters of the implant groups, as determined by interferometry (scanning area of $200 \times 260 \mu \mathrm{m}$ ), and p-values for one-way ANOVA comparisons

\begin{tabular}{lccc}
\hline Group & $S_{a}(\mu m)$ & $S_{d r}(\%)$ & $S_{d s}\left(\mu m^{-2}\right)$ \\
\hline Touareg & $0.890 \pm 0.101^{\mathrm{a}}$ & $45.7 \pm 10.5^{\mathrm{a}}$ & $204316 \pm 16244^{\mathrm{a}}$ \\
ICE & $1.284 \pm 0.210^{\mathrm{b}}$ & $30.9 \pm 7.4^{\mathrm{b}}$ & $167125 \pm 11134^{\mathrm{b}}$ \\
(R)Evolutions & $1.572 \pm 0.227^{\mathrm{c}}$ & $100.2 \pm 21.0^{\mathrm{c}}$ & $174624 \pm 12464^{\mathrm{b}}$ \\
Uniti & $0.433 \pm 0.120$ & $18.2 \pm 4.6^{\mathrm{b}}$ & $207225 \pm 17206^{\mathrm{a}}$ \\
AnyRidge & $1.546 \pm 0.146^{\mathrm{c}}$ & $105.3 \pm 40.8^{\mathrm{c}}$ & $174016 \pm 23030^{\mathrm{b}}$ \\
MIS & $1.159 \pm 0.158^{\mathrm{b}}$ & $28.6 \pm 6.2^{\mathrm{b}}$ & $150184 \pm 16603^{\mathrm{c}}$ \\
Ivory-QSI & $1.286 \pm 0.214^{\mathrm{b}}$ & $33.4 \pm 10.1^{\mathrm{a}, \mathrm{b}}$ & $162203 \pm 17261^{\mathrm{b}, \mathrm{c}}$ \\
Southern & $1.001 \pm 0.095^{\mathrm{a}}$ & $52.8 \pm 7.4^{\mathrm{a}}$ & $214876 \pm 10628^{\mathrm{a}}$ \\
p-value & $<0.001$ & $<0.001$ & $<0.001$ \\
\hline
\end{tabular}

a,b,c Groups denoted with the same superscripted letter indicate absence of statistically significant difference in surface roughness $(P<0.05)$, according to the Tukey's HSD test.

Table 3: Atomic concentration (\%at) of elements according to the sample groups, as determined by EDS analysis. Mean values $( \pm \mathrm{SD})$ from three measurements

\begin{tabular}{|c|c|c|c|c|c|c|c|c|c|}
\hline Group & $\mathrm{Ti}$ & 0 & $A l$ & $\mathrm{Ca}$ & $P$ & Si & $C$ & $F$ & $\mathrm{Fe}$ \\
\hline Touareg & $7.4 \pm 0.9$ & $52.7 \pm 1.6$ & $2.0 \pm 0.3$ & $9.1 \pm 0.6$ & $5.8 \pm 0.2$ & - & $7.4 \pm 0.9$ & - & $0.2 \pm 0.0$ \\
\hline ICE & $79.7 \pm 1.5$ & - & $8.8 \pm 0.4$ & - & - & - & $11.5 \pm 1.6$ & - & - \\
\hline (R)Evolutions & $74.0 \pm 11.5$ & $16.8 \pm 11.8$ & - & - & - & $0.7 \pm 0.7$ & $8.5 \pm 1.2$ & - & - \\
\hline Uniti & $87.4 \pm 2.0$ & - & - & - & - & - & $12.6 \pm 2.0$ & - & - \\
\hline AnyRidge & $55.7 \pm 4.0$ & $36.5 \pm 4.3$ & - & $2.0 \pm 0.1$ & - & - & $5.8 \pm 0.3$ & - & - \\
\hline MIS & $79.3 \pm 1.1$ & - & $8.4 \pm 0.5$ & - & - & - & $12.3 \pm 1.2$ & - & - \\
\hline Ivory-QSI & $77.6 \pm 2.0$ & - & $9.2 \pm 0.4$ & - & - & - & $13.3 \pm 1.9$ & - & - \\
\hline Southern & $25.8 \pm 1.9$ & $44.0 \pm 0.9$ & $11.3 \pm 0.8$ & $0.1 \pm 0.0$ & - & $0.2 \pm 0.1$ & $15.6 \pm 2.3$ & $3.0 \pm 0.5$ & - \\
\hline
\end{tabular}

\section{Scanning Electron Microscopy Analysis}

No standardized method to compare implant surfaces using SEM exists and as such the analysis may be subject to analytical bias. Nevertheless, the use of SEM to complement other more objective tests may highlight important differences in implant surfaces that are otherwise not noted. All the implants included in the study had roughened surfaces, with all having been exposed to a blasting medium to produce irregularities. In most cases, that is, six out of eight samples tested, these implants were also subjected to acid-etching, further enhancing the topographical changes. ${ }^{4,5}$ Two implant surfaces (Uniti and Toureg) were not acid-etched, and one implant surface had undergone additional surface enhancement using a nanostructured calcium coating (AnyRidge). From the SEM analysis, the morphological appearance of the surfaces of Alpha Bio, (R)Evolutions, and MIS implants appeared similar, probably indicating a comparable method in surface treatment. The implant material, types of particles used, and the size and impact velocity may account for the morphological differences seen between these three implants and the Ivory-QSI implant surface. ${ }^{6}$ Not being exposed to acid-etching results in a clear distinction between the Uniti and Toureg surfaces. Even though submitted to sandblasting and acid-etching, Southern implant surfaces resembled sandblasted-only surface. This surface aspect is probably caused by the use of a weak acid mixture, a low etching temperature, or a short etching time. ${ }^{5,7}$ The occurrence of irregular-shaped crystal-like structures on the Touareg surface most likely indicates the presence of residual calcium phosphate $(\mathrm{CaP})$.

\section{Surface Roughness Analysis}

Implant surface roughness is commonly categorized into four groups according to Albrektsson and Wennerberg, ${ }^{8}$ that is, smooth $\left(\mathrm{S}_{\mathrm{a}}<0.5 \mu \mathrm{m}\right)$, minimally rough $\left(\mathrm{S}_{\mathrm{a}}\right.$ between 0.5 and $1.0 \mu \mathrm{m})$, moderately rough $\left(\mathrm{S}_{\mathrm{a}}\right.$ between 1.0 and $2.0 \mu \mathrm{m})$, and rough $\left(S_{a}>2.0 \mu \mathrm{m}\right)$. It is suggested that a $\mathrm{S}_{\mathrm{a}}$ of about $1.5 \mu \mathrm{m}$ results in increased bone-to-implant contact values, increased removal torque, and high clinical success rates for early loaded dental implants. ${ }^{1,9}$

Most of the implants tested showed $S_{a}$ values in the moderately rough range. (R)Evolutions and AnyRidge implants showed values that were close to optimal surface roughness (of approximately $1.5 \mu \mathrm{m}$ ). Uniti and Touareg implants had a mean $S_{a}$ value of less than $1.0 \mu \mathrm{m}$. The fact that these implants were only sandblasted may explain the lower values as compared with the implants that were sandblasted and acid-etched.

Clinical results obtained with minimally or moderately rough implants have shown similar results under normal conditions. However, when placed in areas, such as bone grafts and poor quality bone (type IV), research 
indicates a definitive advantage of moderately rough implants over their minimally rough counterparts. ${ }^{10}$ This is significant for the Uniti implant tested, which showed the lowest $S_{a}$ mean value in the present study. Studies are required to verify whether the Uniti implant has a similar clinical efficacy compared with the implants that have a rougher surface. The Touareg implant, although having a minimally rough surface, displays clinical efficacy similar to that seen for moderately roughened implants. ${ }^{11}$ This may be due to surface coating of $\mathrm{CaP}$, suggesting that surface roughness is not the sole component for successful osseointegration. One study ${ }^{12}$ observed that the addition of a CaP treatment to a dual acid-etched implant surface appeared to increase the extent of bone development after 4 and 8 weeks of healing.

Although $S_{a}$ values have traditionally been used as the hallmark of measuring implant surface roughness, $S_{\mathrm{dr}}$ values seem to have some influence on the success of osseointegration. An $\mathrm{S}_{\mathrm{dr}}$ value of approximately $50 \%$ has been suggested as improving bone formation. ${ }^{13-15}$ Taking this into account, the implants tested fell into three distinct groups, with (R)Evolutions and AnyRidge showing the highest values and ICE, Uniti, and MIS showing the lowest. Southern and Toureg showed values between the two extremes. The Ivory-QSI implant was statistically similar to the lower and middle group.

The combined effect of the $S_{d r}$ and $S_{a}$ values for the implants tested remains to be determined on their clinical efficacy. The Uniti implant was the only implant with both the lowest $S_{a}$ and $S_{d r}$ value, suggesting that this implant may not be as successful in sites of poor bone quality as implants with a rougher surface.

\section{Energy Dispersive X-ray Spectroscopy Analysis}

The EDS analysis revealed that titanium and oxygen were the most prevalent elements detected on the surface of the implants. The calcium levels were the highest for the Touareg implant, reflecting the use of non-washed $\mathrm{CaP}$ blasting process; that is, the surface was not acidetched after the blasting, thereby increasing the residual concentration of the elements $\mathrm{Ca}$ and $\mathrm{P}$ on the surface. This has been shown to enhance biomechanical fixation in animal studies and may suggest that using a combined technique of blasting and acid-etching may not be necessary to improve osseointegration. ${ }^{16}$

The presence of fluoride was noted on the Southern implant surface. Previous studies indicate that fluoridemodified titanium surfaces may increase bone density as well as enhance binding of the bone to the implant surface. ${ }^{17,18}$ It is speculated that the addition of fluoride may lead to improved osteoblastic differentiation as well as increased gene expression, thereby explaining the positive bone response seen. ${ }^{19}$ However, these results are not consistent, with animal studies indicating no significant difference between fluoride-modified and bioinert implant surfaces. ${ }^{20}$

Aluminum was detected on the surface of five implants (Touareg, ICE, MIS, Ivory-QSI, Southern). Some dental implant manufacturers use $\mathrm{Al}_{2} \mathrm{O}_{3}$ to sandblast the machined dental implant before the acid-etching process, because $\mathrm{Al}_{2} \mathrm{O}_{3}$ powder is commercially more easily available and is cheaper than $\mathrm{TiO}_{2}$ powder. However, the sandblasting particles used during the roughening step may not be completely removed from the implant surface during the etching process. ${ }^{4}$ The effects of $\mathrm{Al}_{2} \mathrm{O}_{3}$ are definitely a cause for concern, and it is suggested that the presence of this chemical compound may interfere with the osseointegration process. ${ }^{21}$

Carbon was detected on the surface of all implants. The presence of carbon in different chemical environments is typical for titanium (and other metal) oxide surfaces. A part of this carbon is due to the unavoidable adsorption of ubiquitous hydrocarbons from the atmosphere and a part due to contamination by lubricating fluids and other carbonaceous compounds. ${ }^{22}$ Apart from the chemical significance, pronounced carbon contamination produces effects in in vitro cell adhesion tests ranging from reduced cell adhesion and spreading to cell death. ${ }^{23}$

Silicon was seen on both the Southern and the (R) Evolutions implant surfaces. This indicates that Si was probably used during the blasting process, but inadequate removal during the etching process had resulted in residual material being left behind. ${ }^{24}$ Contamination of biomaterial surfaces with hydrocarbons, molecules, and elements can reduce the surface energy and, thereby, also the potential bio-acceptability. ${ }^{25}$

\section{CONCLUSION}

The implants tested showed varying degrees of surface modification, with most implants having a moderately rough surface. Sandblasted-only implant surfaces had a lower mean value of $S_{a}$ in comparison with sandblasted and acid-etched implant surfaces. AnyRidge and (R)Evolutions had surface roughness close to ideal, as suggested by the literature ( $1.5 \mu \mathrm{m})$. MIS, ICE, and IvoryQSI had moderately rough surfaces that were similar to each other. Southern and Touareg presented a minimally rough surface. Only the Uniti implant was regarded as "smooth." Titanium and oxygen were the most prevalent elements found on the surface. Carbon contamination was detected on the surface of all implants and that of aluminum on five implants (Touareg, ICE, MIS, IvoryQSI, Southern). Ca and P were detected on the surface of Touareg implants, as stated by the manufacturer. The results indicate that implant surface treatment is not 
standardized. This may have clinical implications. Further clinical research is required.

\section{ACKNOWLEDGMENT}

Authors would like to thank Mr. Franscious Cummings (Electron Microscopy Unit, Physics Department, University of The Western Cape) for the SEM images and the EDS analysis.

\section{REFERENCES}

1. Yeo IS. Reality of dental implant surface modification: a short literature review. Open Biomed Eng J 2014 Oct;8:114-119.

2. Chrcanovic BR, Pedrosa AR, Martins MD. Chemical and topographic analysis of treated surfaces of five different commercial dental titanium implants. Mater Res 2012 May-Jun; 15(3):372-382.

3. Wennerberg A, Albrektsson T. Suggested guidelines for the topographic evaluation of implant surfaces. Int J Oral Maxillofac Implants 2000 May-Jun;15(3):331-344.

4. Chrcanovic BR, Leão NLC, Martins MD. Influence of different acid etchings on the superficial characteristics of Ti Sandblasted with $\mathrm{Al}_{2} \mathrm{O}_{3}$. Mater Res 2013 Sep-Oct;16(5):1006-1014.

5. Chrcanovic BR, Martins MD. Study of the influence of acid etching treatments on the superficial characteristics of Ti. Mater Res 2014 Mar-Apr;17(2):373-380.

6. Elias CN, Meirelles L. Improving osseointegration of dental implants. Exp Rev Med Devices 2010 Mar;7(2):241-256.

7. Szmukler-Moncler S, Testori T, Bernard JP. Etched implants: a comparative surface analysis of four implant systems. J Biomed Mater Res B Appl Biomater 2004 Apr;69(1):46-57.

8. Albrektsson T, Wennerberg A. Oral implant surfaces: Part 1review focusing on topographic and chemical properties of different surfaces and in vivo responses to them. Int J Prosthodont 2004 Sep-Oct;17(5):536-543.

9. Roccuzzo M, Aglietta M, Bunino M, Bonino L. Early loading of sandblasted and acid-etched implants: a randomizedcontrolled double-blind split-mouth study. Five-year results. Clin Oral Implants Res 2008 May;19(5):148-152.

10. Del Fabbro M, Rosano G, Taschieri S. Implant survival rates after maxillary sinus augmentation. Eur J Oral Sci 2008 Dec;116(6):497-506.

11. Peck MT, Satti A, Majeed A. A retrospective analysis of early implant failure of the Adin Touareg-X dental implant system. Int J Clin Dent Sci 2014 Sep;5(2):30-35.

12. Goené RJ, Testori $\mathrm{T}$, Trisi $\mathrm{P}$. Influence of a nanometer-scale surface enhancement on de novo bone formation on titanium implants: a histomorphometric study in human maxillae. Int J Periodontics Restorative Dent 2007 Jun;27(3):211-219.

13. Wennerberg A, Albrektsson T, Andersson B, Krol JJ. A histomorphometric and removal torque study of screw-shaped titanium implants with three different surface topographies. Clin Oral Implants Res 1995 Mar;6(1):24-30.

14. Wennerberg A, Albrektsson T, Andersson B. Bone tissue response to commercially pure titanium implants blasted with fine and coarse particles of aluminum oxide. Int J Oral Maxillofac Implants 1996 Jan-Feb;11(1):38-45.

15. Wennerberg A, Albrektsson T, Johansson C, Andersson B. Experimental study of turned and grit-blasted screw-shaped implants with special emphasis on effects of blasting material and surface topography. Biomaterials 1996 Jan;17(1):15-22.

16. Coelho PG, Marin C, Granato R, Giro G, Suzuki M, Bonfante EA. Biomechanical and histologic evaluation of non-washed resorbable blasting media and alumina-blasted/acid-etched surfaces. Clin Oral Implants Res 2012 Jan;23(1):132-135.

17. Taxt-Lamolle SF, Rubert M, Haugen HJ, Lyngstadaas SP, Ellingsen JE, Monjo M. Controlled electro-implementation of fluoride in titanium implant surfaces enhances cortical bone formation and mineralization. Acta Biomater 2010 Mar;6(3):1025-1032.

18. De Bruyn H, Raes F, Cooper LF, ResideG, Garriga JS, Tarrida LG, Wiltfang J, Kern M. Three-years clinical outcome of immediate provisionalization of single OsseoSpeed implants in extraction sockets and healed ridges. Clin Oral Implants Res 2013 Feb;24(2):217-223.

19. Hong YS, Kim MJ, Han JS, Yeo IS. Effects of hydrophilicity and fluoride surface modifications to titanium dental implants on early osseointegration: An in vivo study. Implant Dent 2014 Oct;23(5):529-533.

20. Choi JY, Lee HJ, Jang JU, Yeo IS. Comparison between bioactive fluoride modified and bioinert anodically oxidized implant surfaces in early bone response using rabbit tibia model. Implant Dent 2012 Apr;21(2):124-128.

21. Canabarro A, Diniz MG, Paciornik S, Carvalho L, Sampaio EM, Beloti MM, Rosa AL, Fischer RG. High concentration of residual aluminum oxide on titanium surface inhibits extracellular matrix mineralization. J Biomed Mater Res A 2008 Dec;87(3):588-597.

22. Morra M, Cassinelli C. Evaluation of surface contamination of titanium dental implants by LV-SEM: comparison with XPS measurements. Surf Interface Anal 1997;25(13):983-988.

23. Cassinelli C, Morra M, Bruzzone G, Carpi A, Di Santi G, Giardino R, Fini M. Surface chemistry effects of topographic modification of titanium dental implant surfaces: in vitro experiments. Int J Oral Maxillofac Implants 2003 Jan-Feb;18(1): 46-52.

24. Keller JC, Draughn RA, Wightman JP, Dougherty WJ, Meletiou SD. Characterization of sterilized CP titanium implant surfaces. Int J Oral Maxillofac Implants 1990 Winter;5(4):360-367.

25. Korotin DM, Bartkowski S, Kurmaev EZ, Meumann M, Yakushina EB, Valiev RZ, Cholakh SO. Surface characterization of titanium implants treated in hydrofluoric acid. J Biomater Nanobiotech 2012 Jan;3(1):87-91. 